\title{
TUMOR DE CÉLULAS DE SERTOLI, UN EXTRAÑO TUMOR TESTICULAR. NUESTRA EXPERIENCIA Y REVISION DE LA LITERATURA
}

Ignacio Gómez García, Marta Romero Molina, Antonio López-García Moreno, Elena Buendía González, Emilio Rubio Hidalgo, Eduardo Bolufer, Antonio Sampietro Crespo y Antonio Gómez Rodríguez.

Servicio de Urología Hospital. Virgen de la Salud. Toledo. España.

Resumen.- OBJETIVO: Aportamos dos nuevos casos de tumor testicular de células de Sertoli, realizando búsqueda en Medline y Cochrane de los casos publicados a nivel internacional.

MÉTODOS: Revisión de nuestra serie de neoplasias testiculares, incidencia de los tumores estromales, presentación, clínica, tratamiento y pronóstico, así como de la experiencia reflejada en la literatura.

Ignacio Gómez García

Servicio de Urología

Hospital Virgen de la Salud

Avda. de Barber, s/n

45004 Toledo (España)

naggoga@yahoo.es

Aceptado para publicar: 12 de marzo 2010. 
RESULTADOS: La prevalencia de los tumores testiculares en nuestra área de salud es del 0,09\%, suponiendo el tumor de Sertoli el 2,3\% de ellos. La incidencia es levemente superior a la informada en otros trabajos, con cifras del 0,4\% al 1,5\% de los tumores testiculares en el adulto y hasta el $4 \%$ en los niños. La presentación más habitual es la masa testicular indolora, pudiendo existir semiología secundaria a la producción hormonal.

CONCLUSIONES: El tumor de células de Sertoli presenta una incidencia no superior al $4 \%$ de las neoplasias testiculares. La clínica más habitual es la tumoración indolora, existiendo casos de manifestaciones endocrinas que varían según la edad del paciente Hasta un 10\% de ellos se comportan de manera maligna.

Palabras clave: Neoplasia. Sertoli. Estroma. Testículo.

Summary.- OBJECTIVE: We report two new cases of Sertoli cell testicular tumors, and a Cochrane and Medline search of cases published worldwide.

METHODS: We reviewed our series of testicular tumors, the stromal tumor incidence, clinical presentation, treatment and prognosis, and the experience reflected in the literature.

RESULTS: The prevalence of testicular tumors in our health area is of $0.09 \%$, and $2.3 \%$ of them are Sertoli cell neoplasms. This figure is slightly higher than the found in other series in which Sertoli tumors range from $0.4 \%$ to $1.5 \%$ of testicular malignancies in adults and reach $4 \%$ in children.

CONCLUSIONS: Sertoli cell tumor has an incidence not exceeding 4\%. The most common symptom is a painless mass; in cases with endocrine manifestation, up to $10 \%$ are malignant depending on the age of the patient.

Keywords: Tumor. Sertoli. Stroma. Testicle.

\section{INTRODUCCIÓN}

El tumor de células de Sertoli (TCS) es una neoplasia que deriva de los cordones sexuales del estroma testicular. Es un tipo infrecuente, no existiendo más de 170 casos descritos en la literatura. Representan del 0,4 al $1,5 \%$ de los tumores testiculares en el adulto y hasta el $4 \%$ los niños, suponiendo el $17 \%$ de las neoplasias no germinales $(1,2)$.

\section{MATERIAL Y MÉTODOS}

Desde enero de 1991 a diciembre de 2006 se han diagnosticado en nuestro servicio un total de 86 tumo-

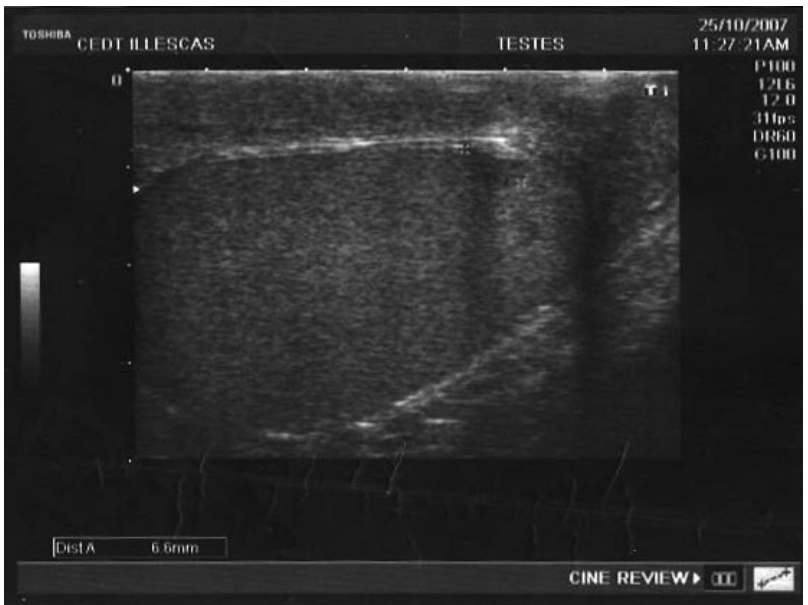

FIGURA 1. Ecografía testicular: Área heterogénea de 1 $\mathrm{cm}$ de diámetro máximo.

res de testículo, dos de los cuales eran de células de Sertoli. La prevalencia de los tumores testiculares en nuestra área de salud es del 0,09\%. La edad media de diagnóstico fue de 32,6 años con rango de 15 a 89 años. El tipo histológico más frecuente fue el germinal $(86,2 \%)$, seguido de linfáticos $(9,6 \%)$ y estromales $(4,2 \%)$. Dentro de los germinales el más habitual fue el seminoma $(38,09 \%)$, con los tumores mixtos en segundo lugar $(36,50 \%)$. En un 15,47\% existía neoplasia intratubular asociada. El TCS supone un 2,3\% de los tumores testiculares en nuestra serie.

El primer paciente, de 21 años, acude a nuestras consultas por dolor testicular derecho de tres meses de evolución. En la exploración física se aprecia tumoración sólida y dolorosa en el testículo derecho. Se realizó una ecografía en la que se apreciaba una imagen en teste derecho de características ecográficas heterogéneas y 3 $\mathrm{cm}$ de diámetro máximo. Los valores de marcadores tumorales (LDH, alfa feto proteína, y BHCG) estaban den-

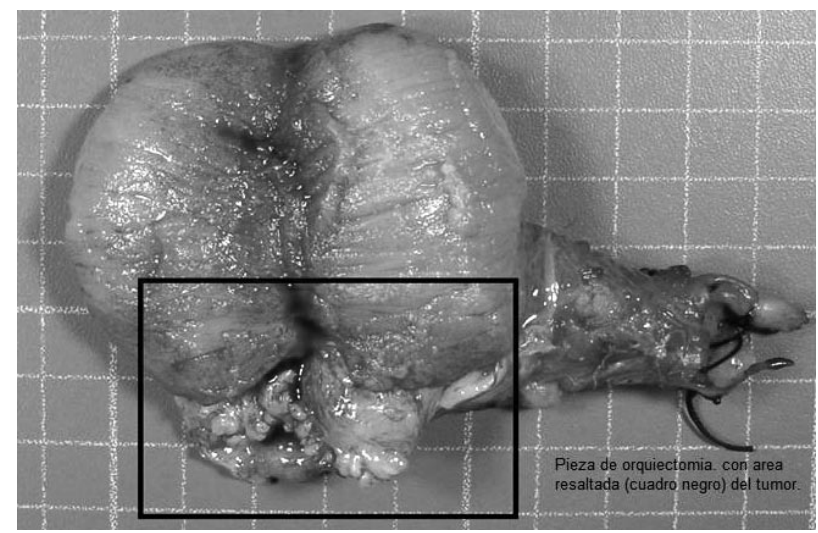

FIGURA 2. Estudio patológico macroscópico: tumoración de $1 \mathrm{~cm}$ aproximado de aspecto amarillento. 
tro de parámetros de la normalidad. Con el diagnóstico de masa testicular se realizó orquiectomía radical, con diagnóstico patológico de TCS. El estudio de extensión mediante TC no evidenció datos de enfermedad a distancia. El paciente no recibió tratamiento coadyuvante, manteniéndose asintomático y libre de enfermedad tras 72 meses de seguimiento.

Nuestro segundo caso es el de un varón de 48 años, con antecedentes de vasectomía doce meses antes, que consulta por dolor testicular derecho de 3 semanas y ginecomastia de 12 meses de evolución. La exploración testicular no proporciona hallazgos patológicos. En la ecografía testicular (Figura 1) se objetiva lesión heterogénea de $1 \mathrm{~cm}$ de diámetro máximo; los marcadores bioquímicos están en el rango normal. Se procede a orquiectomía radical derecha, siendo el informe patológico definitivo de TCS (Figuras 2, y 3). En el estudio de extensión con TC toraco-abdominal no se hallaron datos de enfermedad diseminada. No se pautó tratamiento adyuvante. En la actualidad, tras 40 meses de seguimiento, no ha presentado recidiva, encontrándose asintomático y con mejoría de la ginecomastia.

\section{DISCUSIÓN}

EI TCS fue descrito por primera vez en 1949 por Telium (3), siendo entonces denominado androblastoma. En 1977 Mostofi-Sobin clasificó los tumores del estroma embrionario y los cordones sexuales en tumores de Sertoli, tumores de Leydig y tumores de Sertoli- Leydig. Esta última clasificación fue ampliada en 1998 por Young, incluyendo a los tumores de la granulosa y los mixtos (4).

Los tumores derivados de los cordones sexuales del estroma testicular especializado vienen a representar el $3-4 \%$ de las neoplasias testiculares $(3,5)$, suponiendo

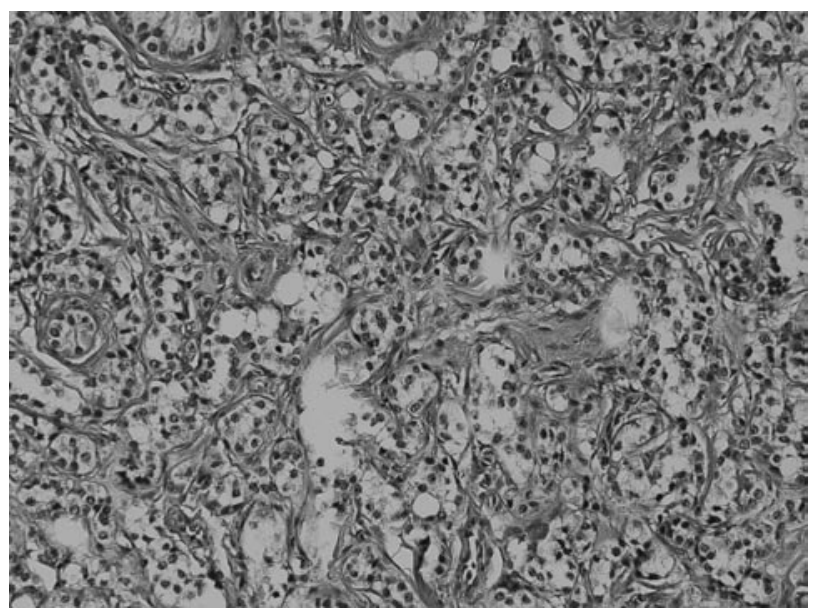

FIGURA 3. Estudio patológico microscópico: Tinción con hematoxilina eosina a 20 aumentos los TCS entre un $0,4 \%$ y un $4 \%(3,5)$. Pueden aparecer a cualquier edad, teniendo dos picos de máxima incidencia: lactantes menores de un año y entre 20 a los 45 años. Es infrecuente su aparición en varones con edad superior a los 50 años (4).

El síntoma más habitual es la tumoración indolora de crecimiento lento (2-6), pudiendo aparecer síntomas y signos derivados de la producción de hormonas. Las alteraciones hormonales más frecuentes son, en niños, la pubertad precoz $y$, en adultos, la ginecomastia e impotencia. El TCS de células grandes calcificadas se suele asociar con acromegalia, hipercortisolemia, pigmentación mucocutánea y síndrome de Peutz-Jeghers. No existen diferencias en cuanto a la lateralidad (7), siendo más frecuente la afectación unilateral que la bilateral.

La ecografía no suele aportar datos orientativos, consiguiéndose el diagnostico definitivo mediante el estudio anatomo-patológico. Los marcadores tumorales suelen ser negativos $(2,8,9)$.

Macroscópicamente, son masas generalmente pequeñas, homogéneas, bien delimitadas y de color amarillo grisáceo. Microscópicamente se caracterizan por estructuras tubulares de células cuboides, que forman cordones sin luz. El estroma está ocupado por trabéculas fibrosas. No existen alteraciones de núcleo celular, apreciándose un nucléolo pequeño. El 33\% de estas neoplasias llevan asociadas células de Leydig, por lo que son considerados tumores mixtos.

Los TCS se clasifican, según Anderson, en tres tipos $(2,10)$ :

1. Tumor de Células de Sertoli clásico (TSC): es el subtipo histológico más común. Suelen diagnosticarse en adultos, siendo excepcional la aparición en niños (7). Entre un 10 y un $30 \%$ se asocian con producción de estrógenos, provocando disfunción endocrina. Es excepcional que sean bilaterales o multicéntricos, no existiendo tendencia a la lateralidad. Youg et al., en su serie de 62 pacientes, describen 4 casos de presentación extratesticular y afectación ganglionar.

\section{TABLA I. FACTORES CLÍNICOS DE MAL PRONÓSTICO}

\begin{tabular}{|c|}
\hline Tumor de células de Sertoli clásico. \\
\hline Edad adulta. \\
\hline Gran tamaño tumoral. \\
\hline Ginecomastia \\
\hline
\end{tabular}


2. Tumor de células de Sertoli grandes calcificadas: descrito por primera vez en 1980 por Proppe y Scully, hasta la actualidad hay descritos en la literatura un total de 62 de estos tumores (7). Histológicamente se visualizan células de citoplasma grande con calcificaciones específicas intratubulares e intensa eosinofilia. Un $60 \%$ suelen ser bilaterales, y un $60 \%$ multifocales. Se considera este subtipo el de mayor agresividad, habiendo casos descritos de malignidad, especialmente en edad adulta $(7,8,11)$. Se diagnostican habitualmente en varones de menos de 20 años, siendo la variante más común en niños $(7,9)$. Clínicamente suelen manifestarse como pubertad precoz (secundaria a la hiperproducción esteroidea). Un 36\% de los casos debutan con síntomas extragonadales, siendo los más comunes el complejo de Carney (tumores testiculares, adrenales, hipofisarios, lesiones pigmentadas cutáneas, mixomas cutáneos y auriculares), el síndrome de Peutz-Jeghers (pigmentación mucocutánea y poliposis intestinal) y la esclerosis tuberosa. Ecográficamente, suelen objetivarse masas testiculares con grandes áreas calcificadas.

3. Tumor de células de Sertoli esclerosante: descrito por primera vez en humanos por Zukerberg en 1991. Es más frecuente en varones adultos. Clínicamente predominan los síntomas locales, siendo excepcional los extragonadales o endocrinológicos. Histológicamente se diferencian de los demás subtipos en la presencia de amplias zonas laminadas de colágeno y la negatividad para citoqueratina. No hay publicados casos de multifocalidad o bilateralidad, existiendo solo un caso descrito de malignidad $(3,7,12)$.

En el análisis inmunohistoquímico muestran positividad a la queratina y vimentina (13); la reacción a las citoqueratinas varía entre los distintos subtipos, siendo positiva en el TCS clásico, variable en el TCS de células calcificadas y negativa en más del $80 \%$ de la variedad esclerosante.

Alrededor de un 10\% se comportan como tumores malignos, considerándose criterios sugestivos de malignidad tamaño mayor de 5 centímetros, presencia de necrosis y atipia e invasión vascular o linfática $(2,4)$. Hasta el momento actual, en la literatura hay 21 casos descritos de TCS malignos $(1,7,8)$. En el $12 \%$ de los tumores de Sertoli aparecen metástasis, siendo los ganglios, huesos, y pulmón sus localizaciones habituales (1) (Tabla I).

Ante cualquier masa testicular, la sospecha inicial será un origen neoplásico, siendo otras posibles causas las infecciones crónicas (brucella y tuberculosis) o agudas (orquiepididimitis).

El diagnóstico diferencial, a nivel patológico, debe realizarse con tumores de células de Leyding, hiperplasia de células de Sertoli, adenoma tubular de Pick (en testículos criptorquídicos), tumores de la granulosa, tumores de Sertoli-Leyding, tumor carcinoide testicular, tumor adenomatoide, y metástasis tumoral (sobre todo del adenocarcinoma prostático).

Los TCS en varones con edad superior a 40 años suelen ser de gran tamaño, con invasión de cubiertas y cordón, y cursan con ginecomastia. Son más agresivos, con frecuente evolución a la malignidad, no existiendo en los casos metastásicos una supervivencia mayor a los 36 meses $(8,9,15,16)$.

El tratamiento es la orquiectomía radical, como en cualquier lesión testicular sospechosa de neoplasia, existiendo autores que defienden la orquiectomía parcial con conservación de tejido testicular en niños por las ventajas estéticas, psicológicas y funcionales (5-9). No se han evidenciado casos de malignización de tumores de células de Sertoli grandes calcificadas en niños, por lo que diversos autores abogan por la abstención de orquiectomía o por la realización de orquiectomía parcial en casos seleccionados $(7,9)$. En 2001 Heidenreich et al (14) evaluaron 73 pacientes con tumores germinales testiculares en los que se preservó tejido testicular, con un promedio de seguimiento de 91 meses. Sólo se objetivaron 4 recaídas, sin influir en la supervivencia global. De esta forma, proponen la cirugía conservadora como una opción terapéutica viable.

Para el tratamiento de los TCS malignos se han utilizado, con desiguales resultados, desde la radioterapia a protocolos de quimioterapia diversos, e incluso linfadenectomía paraaórtica $(4,5,15)$.

Dada la poca casuística de esta estirpe tumoral, y puesto que un $10 \%$ de TCS son malignos, el seguimiento debe de ser de por vida, no existiendo un protocolo descrito para dicho seguimiento.

\section{BIBLIOGRAFÍA Y LECTURAS RECOMENDADÁS (*lectura de interés $y^{* *}$ lectura fundamental)}

**1. Demir A, Önol FF, Türkeri L. Case report: Malignant Seroli cell tumor of the testis in an adult. Int Urol and Nephro, 2003; 35: 515-6.

2. Teryama K, Hirokawa M, Shumizu M. Sertoli Cell Tumor of the testis. Report of a case with Imprint Citology Findings. Acta Cytol, 1998; 42: 1458-60.

*3. Dominguez Molinero JF, Vergara Alcaide E, Fernandez Rodriguez A. Tumor testicular de células de sertoli variedades clinicas patológicas. A proposito de un caso. Actas urol Esp, 1997; 21: 519-23.

*4. Hita Rosino E, López Hidlgo J, Mellado Mesa P, Olivar Buera M. Tumor testicular de células de sertoli. Actas Urol Esp, 2001; 25: 74-77.

**5. de Diego Rodriguez E, Pascual Soria C, Portillo Martin JA. Tumor testicular de células de sertoli esclerosante en paciente VIH. Arch Esp urol, 2001; 54: 1129-32. 
*6. Latiff Conde A, Rach Isla A, García A. Tumor testicular de célula grande calcificante. Reporte de un caso. Arch Esp Urol, 2004; 57: 78-82.

7. Borer JG, Tan PE, Diamond DA. The spectrum of sertoli cell tumors in children. Urologic Clinica of North America, 2000; 27: 529-40.

8. Liu PY, Thorner P. Sonogrphic appearance of sertoli cell tumor with pathologic correlation. Pediatric radiol, 1993; 23: 127.

9. Youg $\mathrm{S}$, Gooneratne $\mathrm{S}$, Strauss FH. Feminizing Sertoli Cell Tumors in boys with Peutz- Jeghers syndrome. Am J Surg Pathol, 1995; 19: 50.

10. Anderson GA. Sclerosing sertoli cell tunor of the testis a distinct histological subtype. J Urol, 1995; 154: 1756.

11. Nogales FF, Andujar M, Zuluaga A. Malignant large cell calcifying sertoli cell tumor of the testis. J Urol, 1995; 153: 1935.

12. Zukerberg LR, Young R H, Scully RE. Sclerosing sertoli cell tumor of the testis: a report of 10 cases. Am J Pathol, 1991; 15: 829.

13. Chang B, Borer J, Tan PE, Daiamond DA. Large Cell Calcifying Sertoli Cell tumor of the testis: case report and review of the literature. Urol, 1998; 52: 520-3.

14. Heidenreich A, Weibach L, Holtl W. Organ sparing surgery for malignant germ cell tumor of the testis. Cancer, 1984; 54: 1574.

**15. Young RH, Koelliker DD, Scully RE. Sertoli Cell tumors of the testis, not otherwise specified. A clinicopathologic analysis of 60 cases. Am J Surg Path, 1998; 22: 709-21.

**16. Pellicé i Vilalta C. Tumors testiculars de cèl.lules de Sèrtoli. Succinta revisió de la literatura i d'autors de l'Estat Espanyol (Periode: 1985 - 2003). Annals d'Urologia, 2005 Vol.5 num.2. 